\title{
HYBRID TIME AND FREQUENCY DOMAIN TECHNIQUE ON MODAL IDENTIFICATION USING AMBIENT VIBRATION TESTS
}

\author{
Tatiana KUROIWA ${ }^{1}$ and Hirokazu IEMURA ${ }^{2}$ \\ ${ }^{1} \mathrm{Ph} . \mathrm{D}$. Student, Graduate School of Civil Engineering, Kyoto University \\ (C1-2, C-Cluster, Katsura Campus, Nishigyo-ku, Kyoto 615-8540, Japan) \\ E-mail: tatiana@catfish.kuciv.kyoto-u.ac.jp \\ ${ }^{2}$ Fellow of JSCE, Professor, Graduate School of Civil Engineering, Kyoto University \\ (C1-2, C-Cluster, Katsura Campus, Nishigyo-ku, Kyoto 615-8540, Japan) \\ E-mail: iemura@catfish.kuciv.kyoto-u.ac.jp
}

\begin{abstract}
In this paper, in order to identify the modal properties of a structure based on the ambient vibration monitoring, an innovative method for modal identification, called Hybrid Time and Frequency Domain Analysis, is described and a full scale test is presented. The method consists of frequency domain analysis for natural frequencies and modal shapes identification; and time domain analysis for the damping estimation. The methodology was tested in a 5 story steel frame structure constructed at the Disaster Prevent Research Institute, Kyoto University, Japan, using ambient vibration testing. The dynamic response was measured with simultaneous sensors in every floor, including ground. The modal shapes results were compared with the FEM and with previous results obtained from monitoring under forced vibration. For the damping estimation, free vibration results were compared with the ambient vibration test. The system identification obtained under ambient vibration tests are in very good agreement with the forced and free vibration tests and with the analytical results.
\end{abstract}

Key Words : ambient vibration, damping estimation, modal identification

\section{INTRODUCTION}

Structural Health Monitoring is becoming a research field of great interest. Practical applications are at present mostly found in aerospace and civil engineering structures field.

The dynamic properties of a structure, obtained from the monitoring, can serve as basis for validating and/or updating analytical models and for identifying damage. The dynamic tests are usually subdivided into two groups: (a) forced vibration tests and (b) ambient vibration tests. The main problem associated to the performance of forced vibration tests in large structures (ex. bridges, high buildings and dam stems) is the difficulty to excite, with sufficient energy and in controlled manner, their most significant modes of vibration. In the ambient vibration, testing a structure can be adequately excited by wind, traffic, and human activities and the resulting motions can be measured with highly sensitive instruments. Expensive and cumbersome devices to excite the structure are therefore not needed. Consequently, the overall cost of the measurements conducted on a large structure is reduced.
This paper describes a numerical methodology in order to identify the modal properties of a structure based on the ambient vibration monitoring. The new Hybrid Time and Frequency Domain methodology consists in uncoupling a multi degree of freedom response in view of obtaining free response of each degree of freedom. The technique applied for damping identification under ambient vibration is the Random Decrement Technique ${ }^{1)}$.

To validate the proposed methodology, a full scale 5 story steel frame structure constructed at the Disaster Prevent Research Institute, Kyoto University, Japan, was monitored under ambient vibration and under free vibration. The results were compared with FEM results and with previous results obtained from monitoring under forced vibration by $\mathrm{Bae}^{2)}$. For the damping estimation, free vibration results were compared with the ambient vibration test.

\section{METHODS}

The methodology consists of three main parts. The first part consists in obtaining the natural fre- 
quencies and modal shapes, in the frequency domain analysis, using cross- and auto-correlation functions. In the second step, in view of validating the modal properties obtained, the response of the system is uncoupled by determining the modal amplitude functions. The third step consists in determining the damping of the structure. Once the system is uncoupled and validated, the random decrement technique, in time domain analysis, is applied to estimate the damping. Each step is described as follows:

\section{(1) Natural frequencies and modal shapes}

Considering that the monitored data are simultaneous, it is possible to calculate the cross- and autocorrelation functions from the time histories, in order to determine the natural frequencies, by use of the following transfer function, $T_{x y}$,

$$
T_{x y}=\frac{P_{x y(f)}}{P_{x x(f)}}
$$

where $f$ is the cyclical frequency in Hz. In a particular case of frame structure, $P_{x y}$ corresponds to the cross spectrum of the ground data and each floor data, and $P_{x x}$ corresponds to the power spectrum of the ground data.

In the following methodology, the mode shapes are obtained from frequency domain:

a) From the responses in time domain, for each floor, are obtained the auto-spectral density. Taking into account that the natural frequencies were already obtained considering the cross correlation between ground and each floor, during the mode shape analysis, only the auto-spectral from $1^{\text {st }}$ to the last floor, in case of building, are necessary.

b) From the Power Spectral Density Functions, corresponding to the determined frequencies, are defined the values $S_{y y}$ that are used to determine the positive modal matrix elements $\phi$, according to the following equation (Bendat \& Pierson ${ }^{4)}$ )

$$
\phi_{i\left(y_{j}\right)}=\left[S_{y_{j} y_{j}\left(f_{i}\right)}\right]^{1 / 2}
$$

where $S_{y y}$ is the output auto-spectral density value at the $i^{\text {th }}$ normal-mode frequency and the $j^{\text {th }}$ location.

c) The phase angles between the simultaneous data have to be obtained in order to identify the positive and negative elements of the modal matrix, and consequently, the full mode shapes. The phase angle between two signals is given by

$$
\phi_{x y}(f)=\tan ^{-1}\left[\frac{Q_{x y}(f)}{C_{x y}(f)}\right]
$$

where, $C_{x y}$ and $Q_{x y}$ are, respectively, the real and the imaginary parts of the cross-correlation function between two time history records $x(t)$ and $y(t)$. In the following example, the $x(t)$ values are corresponding to the $1^{\text {st }}$ floor data, and the $y(t)$ values, to the $2^{\text {nd }}$ to $5^{\text {th }}$ floor.

\section{(2) Uncoupling the response of the system}

The second step, which consists of uncoupling the response of the structure, was actually proposed for validating the described method for determining the mode shapes. It is checked, using the time history data obtained directly from the measurements, in order to uncouple the modes of vibration. Later on, the authors realized that the method is useful for estimation of the modal damping.

In the analysis of dynamic response, the total displacement of a structure is given by the sum of the modal components (Clough \& Penzien ${ }^{3)}$ ):

$$
v=\phi_{1} Y_{1}+\phi_{2} Y_{2}+\ldots+\phi_{n} Y_{n}=\sum_{n=1}^{N} \phi_{n} Y_{n}
$$

For every modal component, the displacements are given by the mode shape vector $\phi_{n}$, multiplied by the modal amplitude $Y_{n}$.

Given the mode shape vectors and the total displacements (measured), the objective of the validation is to obtain the modal amplitude functions, $Y_{n}$, in view of comparing the periods of theses functions with the natural period obtained.

The solution is obtained by solving the following linear system in every instant $t=t_{n}$ :

$$
\left[\begin{array}{l}
v_{D O F 1} \\
v_{D O F 2} \\
v_{D O F 3} \\
v_{D O F 4} \\
v_{D O F 5}
\end{array}\right]_{t=t_{n}}=[M]_{5 x 5}\left[\begin{array}{l}
Y_{1\left(t=t_{n}\right)} \\
Y_{2\left(t=t_{n}\right)} \\
Y_{3\left(t=t_{n}\right)} \\
Y_{4\left(t=t_{n}\right)} \\
Y_{5\left(t=t_{n}\right)}
\end{array}\right]
$$

where $[M]_{n \times n}$ is the matrix composed by the mode shape vectors $\phi_{n}$ as column elements.

\section{(3) Damping estimation}

Cole ${ }^{1)}$ introduced the Random Decrement technique as a method to transform a random time series into a free decay of the structure. The concept is not difficult to understand if one thinks that the response of a system to random input loads is, in each time instant $t$, composed by three parts: the response of the initial displacement; the response to an initial velocity; and the response to the random input loads between the initial state and the time instant $t$. By averaging a large number of time segments of the 


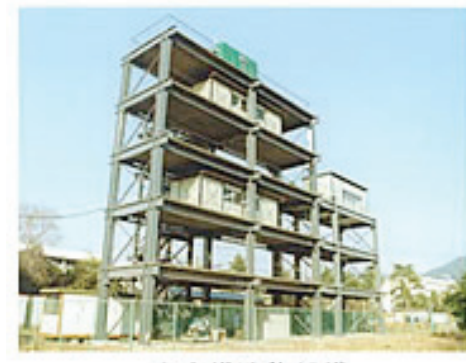

Fig. 1 View of five story steel frame.

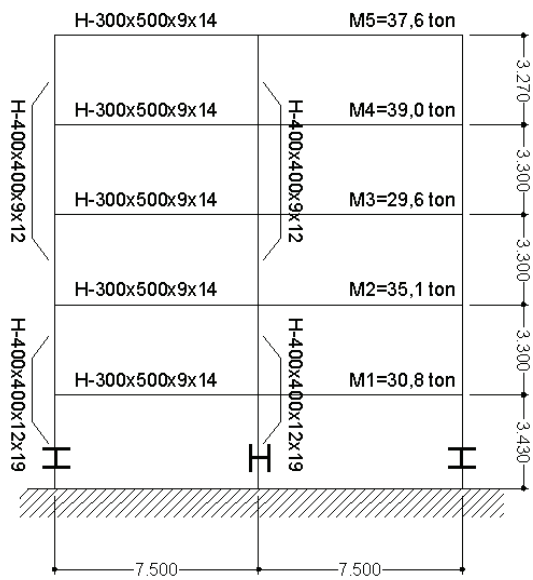

Fig. 2 Elevation view.

response with the same initial condition, the random part of the response will have a tendency to disappear from the average, and what remains is the response of the system to the initial conditions. The application of this method is not widely used because of the limitation of its application only for single degree of freedom structure. But in conjunction with the frequency domain analysis and with the uncoupling process, it is applicable not only in view of obtaining the free vibration response, but also in view of the another effect of the time segments averaging, that is the noise reduction.

For a single degree-of-freedom under free vibration, the traditional equation for determining the modal damping, $\zeta$, is given by Equation (6), called logarithm decrement. $T_{d}$ is the period of time between instants $k$ and $k+1$

$$
\ln \left(\frac{A_{k}}{A_{k+1}}\right)=\zeta \omega_{n} T_{d}=\frac{2 \pi \zeta}{\sqrt{1-\zeta^{2}}}
$$

\section{FULL SCALE TEST}

\section{(1) Description of frame model}

Test frame is the five-story steel structure shown in Fig. 1 and the elevation view, with cross section of members is shown in Fig. 2.

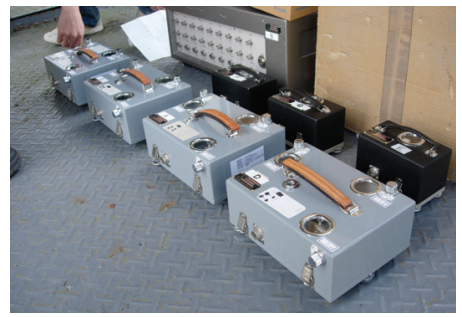

Fig. 3 Sensors.

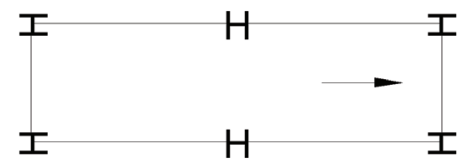

Fig. 4 Typical floor plan and sensor location.

This structure was modeled with two-dimensional beam elements. All members with rigid connections. As for the external columns, $1^{\text {st }}$ and $2^{\text {nd }}$ floors, the total geometric moment of inertia was considered $4.054 \times 10^{-4} \mathrm{~m}^{4}$ and from $3^{\text {rd }}$ to $5^{\text {th }}$ floors, $2.560 \times 10^{-4}$ $\mathrm{m}^{4}$. As for the internal columns, $1^{\text {st }}$ and $2^{\text {nd }}$ floors, $1.199 \times 10^{-3} \mathrm{~m}^{4}$ and from $3^{\text {rd }}$ to $5^{\text {th }}$ floors, $8.026 \times 10^{-4}$ $\mathrm{m}^{4}$.

The floors are consisted of two steel beams and a reinforced concrete slab. In view of the difficulties to evaluate the degree of interaction between slab and beam, were compared two different inertia for the beam, $1.15 \times 10^{-3} \mathrm{~m}^{4}$ and $2.31 \times 10^{-3} \mathrm{~m}^{4}$, which represent the total geometric moment of inertia of the only two steel beams and for full interaction between the slab concrete and beams, respectively. The Young's modulus of concrete and steel was considered respectively $1.8 \times 10^{10} \mathrm{~N} / \mathrm{m}^{2}$ and $2.1 \mathrm{x}$ $10^{11} \mathrm{~N} / \mathrm{m}^{2}$.

The total mass per floor, including equipments, was considered according to $\mathrm{Bae}^{2)}$ as following: $1^{\text {st }}$ floor, $m_{1}=37600 \mathrm{~kg} ; 2^{\text {nd }}$ floor, $m_{2}=39000 \mathrm{~kg} ; 3^{\text {rd }}$ floor, $m_{3}=29600 \mathrm{~kg} ; 4^{\text {th }}$ floor, $m_{4}=35100 \mathrm{~kg} ; 5^{\text {th }}$ floor, $m_{5}=30800 \mathrm{~kg}$.

\section{(2) Instrumentation}

The instruments used for the dynamic measurements of the structure were uni- and tri-axial sensors (Fig. 3) with velocity output data (VCT Corp, models UP-255S/ UP-252), cables, A/D converter, amplifier and a laptop computer for the data acquisition and data storage.

The sampling frequency of 100 and $200 \mathrm{~Hz}$ were considered.

Every floor and the ground level were monitored simultaneously. In order to capture the translational mode in the longitudinal direction, the sensors were located as shown in Fig. 4.

More details about the instrumentation and the comparison between simultaneous and non simultaneous monitoring are described by Kuroiwa \& Ie- 
Table 1 Comparison between ambient vibration, forced vibration and finite element model results.

\begin{tabular}{cllll}
\hline \multicolumn{5}{c}{ Natural Frequencies $(\mathrm{Hz})$} \\
\hline Mode & AVM & Forced & $\mathrm{FEM}_{1}$ & $\mathrm{FEM}_{2}$ \\
1 & 1.76 & 1.69 & 1.69 & 1.98 \\
2 & 5.27 & 5.18 & 5.22 & 5.92 \\
3 & 8.79 & 8.72 & 9.26 & 10.19 \\
4 & 13.67 & 13.60 & 13.26 & 13.90 \\
5 & 17.96 & 17.80 & 17.75 & 18.17 \\
\hline
\end{tabular}

mura $^{5)}$

\section{(3) Modal identification}

The technique described was used to perform modal identification. The software Matlab, was used to obtain the power spectral densities.

\section{a) Natural frequencies}

The results of natural frequencies obtained from ambient vibration test are presented in Table 1, and they are compared with the results obtained from forced and controlled vibration by $\mathrm{Bae}^{3)}$, and with the finite element models.

The differences between the ambient vibration and forced vibration results were very small, it differs less than $4 \%$. By comparing the finite element models and the tested results, it is observed that for the $\mathrm{FEM}_{1}$, in which was ignored the full interaction between concrete slab and steel beam, the results were closer to the ambient and forced vibration than the results for the $\mathrm{FEM}_{2}$, with full interaction between slab and beams. The difference between $\mathrm{FEM}_{1}$ and experimental results was found about $5 \%$ for the $3^{\text {rd }}$. mode.

\section{b) Mode shapes}

In the frequency domain, corresponding to 5 natural frequencies ( $i^{\text {th }}$ normal-mode frequency) already defined, were obtained the auto-spectral density values for every floor $\left(j^{\text {th }}\right.$ location). Normalizing the results, the following matrix, with only positive values were obtained

$$
M=\left[\begin{array}{ccccc}
1 & 0.85 & 0.57 & 0.39 & 0.17 \\
0.9 & 0.09 & 1 & 0.63 & 0.25 \\
0.72 & 0.77 & 0.61 & 1 & 0.89 \\
0.45 & 1 & 0.65 & 0.14 & 1 \\
0.21 & 0.63 & 0.75 & 1 & 0.99
\end{array}\right]
$$

By application of Equation (3), the phase angle matrix was obtained:

$$
\theta=\left[\begin{array}{ccccc}
2.41 & 179.98 & 1.39 & 179.68 & 16.94 \\
2.06 & 179.53 & 178.9 & 3.47 & 171.10 \\
2.18 & 0.71 & 179.71 & 176.89 & 1.79 \\
1.32 & 0.27 & 3.29 & 179.12 & 178.45 \\
0 & 0 & 0 & 0 & 0
\end{array}\right]
$$

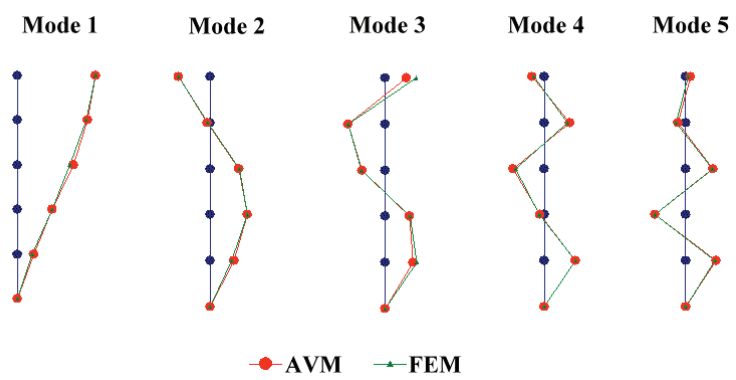

Fig. 5 Comparison of Mode Shapes.

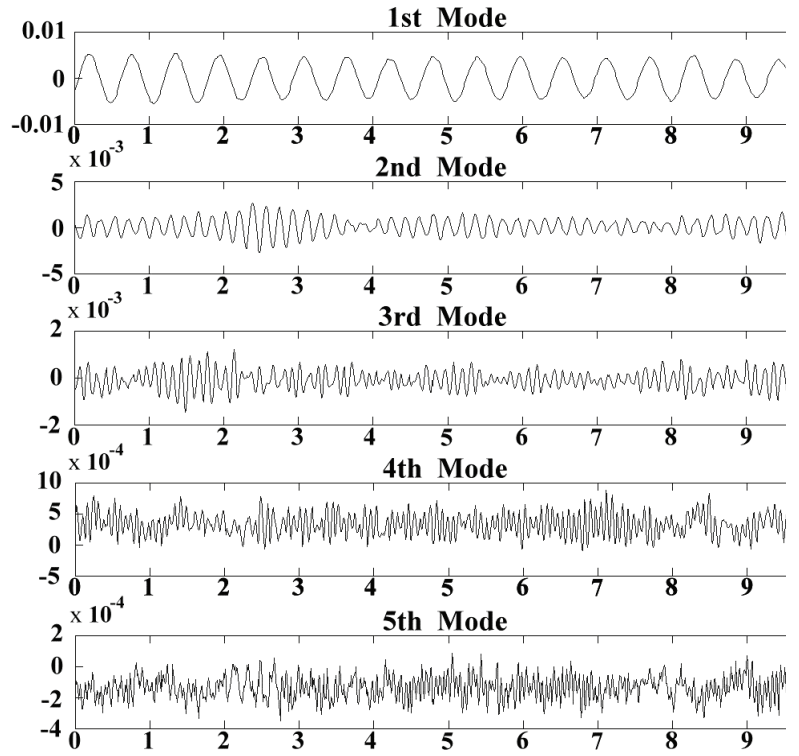

Fig. 6 Modal amplitude functions $\mathrm{x}$ time.

Elements with value close to 180 , we assume as negative value, and close to 0 , as positive. Fig. 5 shows the mode shapes obtained based on Ambient Vibration and Finite Element Model.

\section{c) Uncoupling the modes}

The modal amplitude functions obtained are shown in Fig. 6. The average periods and frequencies for each mode are given in the Table 2.

By comparing the average frequencies in Table 2, with the natural frequencies obtained by application of the Power Spectral Analysis of AVM presented in Table 1, can be observed that the results are in very good agreement, showing that the method to identify the mode shapes has been checked and validated.

\section{d) Damping estimation}

The flow-chart in the Fig. 7 summarizes the numerical procedure to analyze the results from the experimental tests in view of estimating the damping properties. In this flow-chart, two types of excitation are considered, the ambient vibration and the free vibration. The idea of comparing both comes from the necessity of having a reference damping property of the structure to observe if the proposed 
Table 2 Validation Test - natural periods and frequencies.

\begin{tabular}{ccc}
\hline Mode & $\begin{array}{c}\text { Average } \\
\text { Period }(\mathrm{s})\end{array}$ & $\begin{array}{c}\text { Average } \\
\text { Frequency }(\mathrm{Hz})\end{array}$ \\
\hline $1^{\text {st }}$ & 0.57 & 1.75 \\
$2^{\text {nd }}$ & 0.18 & 5.55 \\
$3^{\text {rd }}$ & 0.118 & 8.45 \\
$4^{\text {th }}$ & 0.073 & 13.69 \\
$5^{\text {th }}$ & 0.054 & 18.37 \\
\hline
\end{tabular}

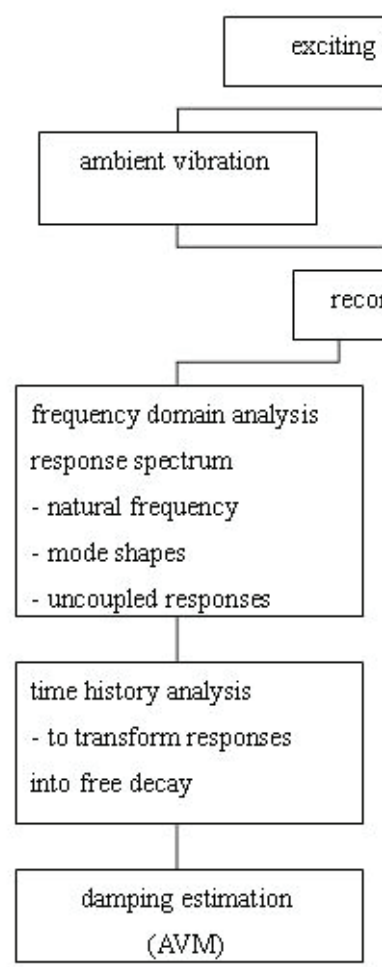

Fig. 7 Flow-chart of the damping identification tests.

method shows a good result for the estimation of the damping properties by comparing with the free vibration results. The estimation of damping through free vibration presents high level of reliability, in view that the amplitude is much higher, so the noise has not large influence in the response. Furthermore, under ambient vibration, the decay of the damping is clear and directly observed from the measured response data, while from the ambient vibration, as shown in the Fig. 7, the proposed numerical methodology is applied to first uncouple the modes, and then transform the responses into free decay.

The simulation of the free vibration was obtained after man made excitation on the top of the building. In this simulation 3 or 4 students moved theirs bodies during repeated intervals of 15-30 sec, and when they stopped the movement, the structure still moving under free vibration. In the Fig. 8, a sample of the direct response from the measured data is plotted for the free vibration condition. In the Fig. 9, a sample of the final result obtained after the application of the proposed method is plotted.

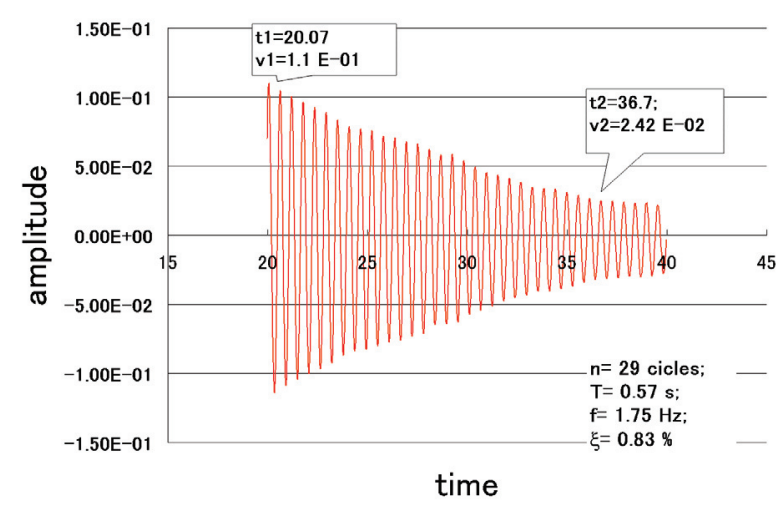

Fig. 8 Free Vibration: Modal amplitude functions $x$ time.

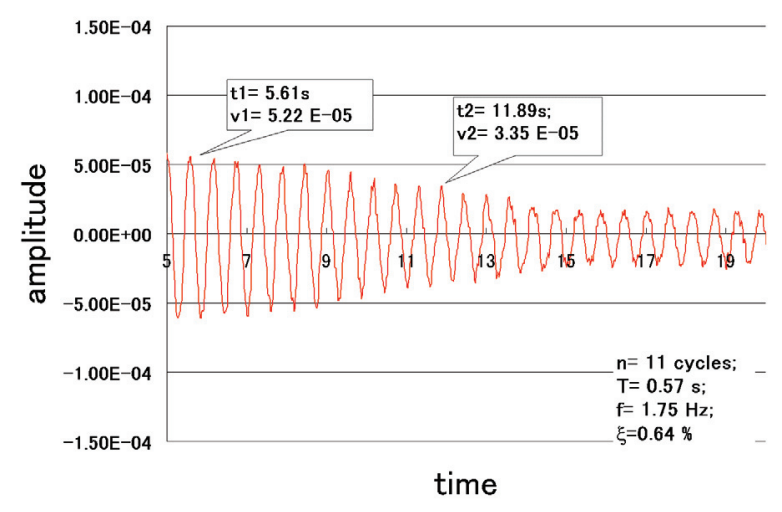

Fig. 9 Ambient vibration: Modal amplitude functions $\mathrm{x}$ time.

From those graphs, the modal damping is estimated using the Equation (6). The modal damping of the individual plots are, for the free vibration results $0.83 \%$, and for the ambient vibration case, $0.64 \%$. The average results of the total measured data are for the ambient vibration $0.71 \%$ and for the free vibration $0.83 \%$.

\section{CONCLUSION}

A new methodology was presented in view of determining the modal properties of structure under Ambient Vibration, including the natural frequencies, modal shapes and modal damping.

A full scale structure was monitored under ambient vibration and under free vibration. The natural frequencies and the modal shapes identification were compared with the results obtained from previous study, in which the external force was a mass exciter, with controlled excitation. The differences were very small, varying between $0.5 \%$ and $4 \%$. The results were also compared with the FEM, considering or not full interaction between the concrete slab and the steel beams. The FEM in which was ignored the full interaction, best represents the monitored results.

The mode shapes and natural frequencies obtained were checked by uncoupling the recorded 
time histories data. The results were in very good agreement with the results obtained from AVM.

The modal damping was estimated after application of the modal decomposition and random decrement technique, and for the ambient vibration monitoring, the averaged result was found equal to $0.71 \%$. It is largely known that the estimation of damping through free vibration presents high level of reliability, in view that the amplitude is much higher, so the noise has not large influence in the response. Furthermore, under free vibration, the decay of the damping is clear and directly observed from the measured response data. For those reasons, the free vibration of the story frame was also monitored, in view of serving as basis to compare with the ambient results. For the free vibration, the average of first modal damping obtained was $0.83 \%$. Only the $1^{\text {st }}$. modal damping properties were compared, due to difficulties to excite the structure by man made vibration to reach the resonance with the higher modes.

The variation on temperature is not considered during the analysis. The measured data were collected under the same temperature conditions when used for comparisons.

ACKNOWLEDGEMENT: The authors would like to express sincere gratitude to Professor Y. Suzuki and H. Kawase from Kyoto University, for providing the use of the structure and the instrumentation.
Thanks to Mr. Mukaibo and Ms. A. Shirayama for providing all documentation available about the 5 story-steel frame, and for preparing all instrumentation and for helping during the monitoring.

We also thank Professor A. Toyooka, Mr. Morimoto, Mr. Y. Shiguetomi, Mr. M. Higuchi, Mr. Y. Imoto, Ms. F. Taya, Mr. T. Shitanishi, Mr. T. Watajima, and Mr. M. Yokita for invaluable helping during the experiment days.

Our gratitude to Professor A. Igarashi for invaluable commentaries about the validation of modal shapes methodology and for helping during the experiment days.

\section{REFERENCES}

1) Cole, H. A.: On-the-line analysis of the random vibrations, AIAA, ASME 9th Structure, Structural Dynamics and Materials, Paper No. 68-228, 1968.

2) Bae, G.: Study on parameter identification and seismic response control of building structures, $\mathrm{PhD}$ Thesis, Disaster Prevention Research Institute, Kyoto University, Japan, 1999.

3) Clough, R.W. and Penzien, J.: Dynamics of Structures, McGraw-Hill Ltd., 1975.

4) Bendat, J.S. and Piersol, A.G.: Engineering Applications of Correlation and Spectral Analysis, 1993.

5) Kuroiwa, T. and Iemura, H.: System Identification of 5 Story Steel Frame, Proceedings of The Nineteenth KKCNN Symposium on Civil Engineering, pp.81-84, Kyoto, Japan, Dec. 2006.

(Received September 5, 2008) 